\title{
Equilibrium and Kinetic Studiès on the Separation of Uranium and Thorium from Nitric Acid Medium by Liquid Emulsion Membrane Based on Trioctylphosphine Oxide Extractant
}

\author{
Sohair A. El-ReEfy', Yasser T. Selim and Hisham F. Aly \\ Hot Laboratories Centre, Atomic Energy Authority, 13759-Egypt
}

\begin{abstract}
It was found that the extraction percent ( $E \%$ ) values of $\mathrm{U}(\mathrm{VI}), \mathrm{Th}, \mathrm{Zr}$ and $\mathrm{Fe}(\mathrm{III})$ from $0.1 \mathrm{~mol} \mathrm{dm}^{-3}$ (M) $\mathrm{HNO}_{3}$ solution by $0.1 \mathrm{M}$ TOPO in cyclohexane solution are $98,78,85$ and $85 \%$, respectively. Among these elements, only U(VI) and Th were found to be stripped from their organic phase by $0.1 \mathrm{M}$ sodium citrate solution. Cerium, copper and cadmium were not extracted by trioctylphosphine oxide (TOPO) under similar conditions. Based on these equilibrium results, a liquid emulsion membrane (LEM) was prepared from TOPO/Span 80/sodium citrate and the factors affecting its stability were studied. Permeation of U(VI) into this membrane was kinetically studied in detail. Its forward permeation rate was found to be mainly dependent on TOPO concentration and slightly dependent on U(VI) and $\mathrm{HNO}_{3}$ concentration of the external phase. Permeation results showed that it is possible to recover $98 \%$ of U(VI) and $82 \%$ of Th from $0.1 \mathrm{M} \mathrm{HNO}_{3}$ solution containing $\mathrm{Ce}, \mathrm{Zr}, \mathrm{Fe}(\mathrm{III}), \mathrm{Cd}$, and $\mathrm{Cu}$ by the membrane. The recovered $\mathrm{U}(\mathrm{VI})$ and $\mathrm{Th}$ were contaminated with less than $2 \%$ of $\mathrm{Fe}(\mathrm{III})$.
\end{abstract}

Keywords Liquid emulsion membrane, uranium(VI) and thorium separation, trioctylphosphine oxide, nitric acid, membrane stability, permeation kinetics

Since $\mathrm{Li}$ in $1968^{1}$ invented the use of liquid emulsion membrane (LEM) as a new separation technique, many investigators have studied the separation of metals by LEM with special reference to the separation of uranium. In this respect, Macasek et al. ${ }^{2}$ presented various emulsion systems with liquid membranes containing different extractants (carriers), such as trioctylphosphine oxide (TOPO), tributyl phosphate (TBP), Kelex-100 and di-2ethylhexyl phosphoric acid (HDEHP) for U(VI) permeation from sodium sulfate solutions. They reported that the use of HDEHP as a membrane carrier encapsulated in the membrane with a solution of $\mathrm{H}_{2} \mathrm{SO}_{4}$ or $\mathrm{H}_{3} \mathrm{PO}_{4}$ is the most effective system. Yoo et al. ${ }^{3}$ studied the separation of $\mathrm{U}$ from a solution of $\mathrm{H}_{3} \mathrm{PO}_{4}$ by LEM containing a combined extractant of HDEHP and TOPO. They found that the mass transfer rate of $U$ increased with temperature. The complexation of $U$ by HDEHP/TOPO was favored at low temperatures, whereas stripping was favored at high temperatures. Both the diffusion of uranyl complex and stripping were considered as the simultaneous rate controlling steps. An improved emulsion extraction process was studied for recovery of $U$ from a wet process phosphoric acid (WPPA) by adding excess oxidizing agent to the WPPA feed using an LEM composed of HDEHP and TOPO., 4 High levels of $U$ extraction and concentration were obtained.

\footnotetext{
$\dagger$ To whom correspondence should be addressed.
}

In previous publications ${ }^{6,7}$, the permeation of $T h$ from a dilute $\mathrm{HCl}$ medium by LEM containing HDEHP in cyclohexane as a carrier, polyethylene glycol dioleate as a surfactant, and $\mathrm{HCl}$ as a stripping agent was investigated. Based on this system, a method for separation of trace Th-234 from its parent $U$ in macroamounts was developed using a batch technique. ${ }^{6}$ Comparative studies between column and batch LEM techniques for recovery of Th-234 from natural uranium were carried out. ${ }^{7}$

The present work is directed mainly to investigate the possible recovery of $\mathrm{U}(\mathrm{VI})$ and $\mathrm{Th}$ from $\mathrm{Zr}, \mathrm{Ce}, \mathrm{Fe}(\mathrm{III})$, $\mathrm{Cu}$, and $\mathrm{Cd}$ in a nitrate medium using TOPO as a carrier in LEM. Detailed investigations on the stability of the membrane system were performed.

\section{Experimental}

\section{Chemicals and reagents}

The extractant trioctylphosphine oxide (TOPO) and the cyclohexane were purchased from Aldrich. The surfactants were Sorbitan monooleate (Span 80), Sorbitan monolaurate (Span 20), polyoxyethylene trioleate (Tween 85) and Arlacel A* (Biochemical reagent) which were supplied from Fluka AG. The other chemicals and reagents used were of A.R. grade.

\section{Membrane preparation}

Unless otherwise stated the LEM used was prepared by 
mixing $25 \mathrm{~cm}^{3}$ of $0.1 \mathrm{M}$ TOPO in cyclohexane with $4 \%$ by volume of Span 80 . To this mixture, $25 \mathrm{~cm}^{3}$ of $0.1 \mathrm{M}$ sodium citrate solution was added. The emulsification was performed with an ultra high speed motor equipped with a specially designed bladed impeller stirrer. A stirring speed of $7000 \mathrm{rpm}$ for 3-5 min was used and the mixture was cooled during emulsification.

\section{Procedures}

Batch liquid-liquid extraction experiments were carried out by mixing equal volumes of the organic phase and the aqueous phase $\left(5 \mathrm{~cm}^{3}\right.$ each) containing the metal ions, U(VI), Th, $\mathrm{Zr}, \mathrm{Ce}, \mathrm{Fe}(\mathrm{III}), \mathrm{Cu}$ or $\mathrm{Cd}$ of concentration of $0.02 \mathrm{M}$, unless otherwise stated. Equilibrium was attained by shaking the two phases for $30 \mathrm{~min}$ using a mechanical shaker. Known sample portions from the aqueous phase were taken for metal ion determination before and after equilibration to determine the extraction percent in the organic phase. The distribution ratio, $D$, was calculated from the ratio of metal ion concentration in the organic phase to that in the aqueous phase.

In permeation experiments, a known volume of the prepared membrane was dispersed in a thermostated vessel containing a known volume of the external phase, $\mathrm{HNO}_{3}$, containing the metal ions under investigation. The mixture was agitated and samples were drawn from the external phase after known time intervals for determining the element concentration. Uranium(VI), $\mathrm{Ce}$ and $\mathrm{Zr}$ were determined in different samples spectrophotometrically using Arsenazo-III and Th with Thoron-I. Cadium, $\mathrm{Cu}$ and $\mathrm{Fe}(\mathrm{III})$ were determined by atomic absorption spectrometry.

\section{Results and Discussion}

\section{Liquid-liquid extraction}

Extraction equilibrium was first examined to identify the extraction behavior and the suitable conditions for $\mathrm{U}(\mathrm{VI})$ and Th extraction from $\mathrm{HNO}_{3}$ medium containing other elements with a solution of TOPO in cyclohexane.

The effect of $\mathrm{HNO}_{3}$ concentration of the range $0.2-$ $11.0 \mathrm{M}$ on the extraction of $0.02 \mathrm{M}$ of both $\mathrm{U}(\mathrm{VI})$ and $\mathrm{Th}$ with $0.05 \mathrm{M}$ TOPO was studied. The results obtained showed that the extraction percent $(E \%)$ increases with the increase in $\mathrm{HNO}_{3}$ concentration to reach a maximum value of approx. $98 \%$ for $\mathrm{U}(\mathrm{VI})$ at $0.1 \mathrm{M} \mathrm{HNO}_{3}$ and approx. $78 \%$ for Th at $1.0 \mathrm{M} \mathrm{HNO}_{3}$. This is followed by a gradual decrease for both elements with further increase in $\mathrm{HNO}_{3}$ concentration up to $11 \mathrm{M}$ (Fig. 1).

The effect of TOPO concentration on the extraction of $0.02 \mathrm{M}$ of both $\mathrm{U}(\mathrm{VI})$ and $\mathrm{Th}$ from two different $\mathrm{HNO}_{3}$ concentrations $(0.1$ and $5.0 \mathrm{M})$ is given in Fig. 2 as a $\log -\log$ relation between the distribution ratio, $D$, and [TOPO]. Straight lines were obtained with slopes equal to one for $\mathrm{U}(\mathrm{VI})$ and equal to 3 for $\mathrm{Th}$, from the two $\mathrm{HNO}_{3}$ concentrations.

Since TOPO is known to extract metal species as ion association complexes and from the slopes obtained, the

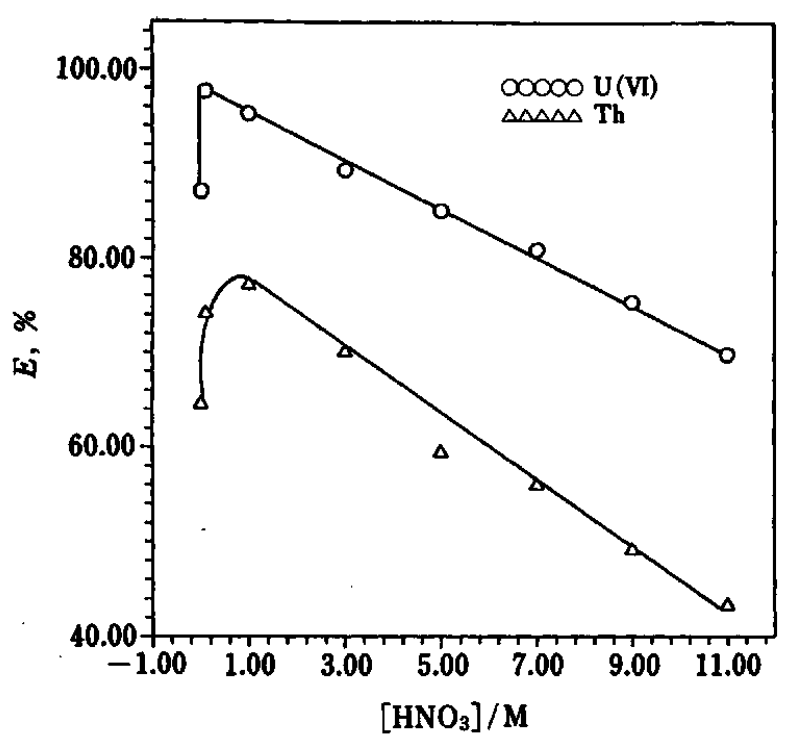

Fig. 1 Effect of nitric acid molarities on the extraction \% of $0.02 \mathrm{M}$ of $\mathrm{U}(\mathrm{VI})$ and $\mathrm{Th}$ by $0.05 \mathrm{M}$ TOPO in cyclohexane.

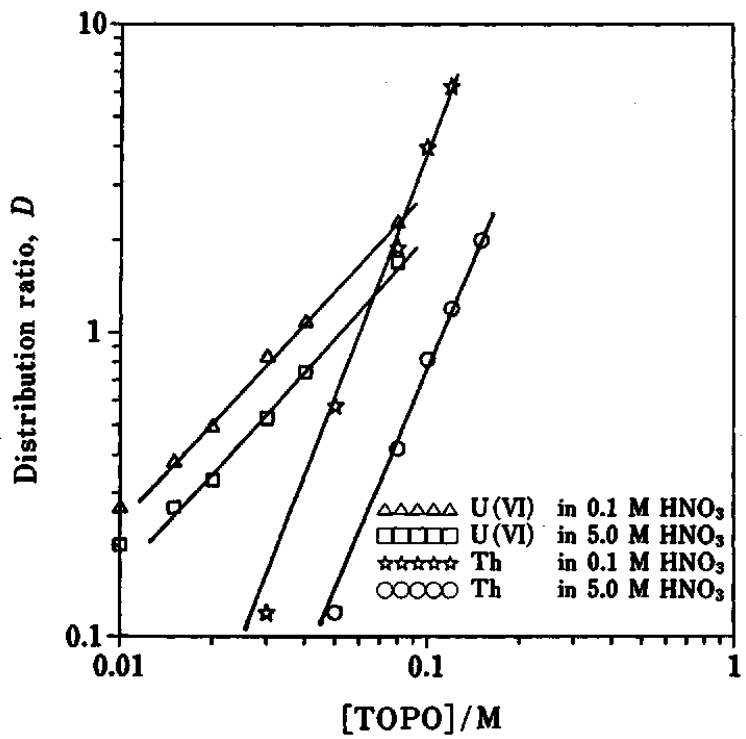

Fig. 2 Effect of TOPO concentration on the distribution of $0.02 \mathrm{M}$ of $\mathrm{U}(\mathrm{VI})$ and $\mathrm{Th}$ from 0.1 and $5 \mathrm{M} \mathrm{HNO}_{3}$ solutions.

following extraction equilibria are suggested:

$$
\mathrm{UO}_{2}\left(\mathrm{NO}_{3}\right)_{2}+\overline{\mathrm{TOPO}} \rightleftharpoons \overline{\left.\mathrm{UO}_{2}(\mathrm{NO})_{3}\right)_{2} \cdot \mathrm{TOPO}}
$$

for U(VI) extraction, and

$$
\mathrm{Th}\left(\mathrm{NO}_{3}\right)_{4}+3 \overline{\mathrm{TOPO}} \rightleftharpoons \overline{\mathrm{Th}\left(\mathrm{NO}_{3}\right)_{4} \cdot 3 \mathrm{TOPO}}
$$

for Th extraction, where a bar above indicates the organic phase.

Among these main extracted species $\mathrm{UO}_{2}\left(\mathrm{NO}_{3}\right)_{2}$, TOPO and $\mathrm{Th}\left(\mathrm{NO}_{3}\right)_{4}$, TOPO were further verified by loading experiments which gave maximum loading of 
Table 1 Effect of different reagents on stripping of U(VI), $\mathrm{Th}, \mathrm{Fe}(\mathrm{III})$ and $\mathrm{Zr}$ from $0.1 \mathrm{M}$ TOPO in cyclohexane ${ }^{a}$

\begin{tabular}{lcccc}
\hline \multirow{2}{*}{ Stripping reagent } & \multicolumn{4}{c}{$\%$ Stripped } \\
\cline { 2 - 5 } & $\mathrm{U}(\mathrm{VI})$ & Th & Fe(III) & $\mathrm{Zr}$ \\
\hline $0.1 \mathrm{M} \mathrm{Na}$ acetate & 0.0 & 15 & 0.0 & 0.0 \\
$0.1 \mathrm{M} \mathrm{Na}$ oxalate & 0.0 & 15 & 0.0 & 0.0 \\
$0.1 \mathrm{M} \mathrm{Na}$ citrate & 82.0 & 55 & 0.0 & 0.0 \\
$0.5 \mathrm{M} \mathrm{HCl}_{0.5 \mathrm{H}_{2} \mathrm{SO}_{4}}^{35.0}$ & 80 & 44 & 0.0 \\
& 64.0 & 80 & 86 & 0.0 \\
\hline
\end{tabular}

a. Organic to aqueous phase volume ratio of 1.0.

U(VI) from $\mathrm{HNO}_{3}$ solutions when the ratio of U(VI) to TOPO was $1: 1$, and maximum loading of $T h$ when the ratio was $1: 3$.

The effect of temperature on the extraction of both $\mathrm{U}(\mathrm{VI})$ and $\mathrm{Th}$ was also studied in the temperature range $30-60^{\circ} \mathrm{C}$. The results obtained showed that the temperature has only a slight effect on the extraction of both elements.

The extraction of $\mathrm{Ce}, \mathrm{Zr}, \mathrm{Fe}$ (III), $\mathrm{Cu}$, and $\mathrm{Cd}$ from $0.1 \mathrm{M} \mathrm{HNO}_{3}$ solution by $0.1 \mathrm{M}$ TOPO in cyclohexane was investigated. It was found that $\mathrm{Ce}, \mathrm{Cu}$ and $\mathrm{Cd}$ were not extracted, while $c a .85 \%$ of both $\mathrm{Zr}$ and $\mathrm{Fe}$ (III) were extracted.

Aqueous solutions of $\mathrm{HCl}, \mathrm{H}_{2} \mathrm{SO}_{4}$, sodium oxalate, sodium acetate and sodium citrate were examined as stripping agents for $\mathrm{U}(\mathrm{VI}), \mathrm{Th}, \mathrm{Zr}$ and $\mathrm{Fe}(\mathrm{III})$ recovery from their organic phases (Table 1). From this table, it is clear that $\mathrm{Zr}$ was not stripped by any of the reagents used. When $0.5 \mathrm{M} \mathrm{HCl}$ or $\mathrm{H}_{2} \mathrm{SO}_{4}$ solution was used, U(VI), Th and Fe(III) were stripped to different extents. On the other hand, $0.1 \mathrm{M}$ sodium citrate solution stripped only $82.0 \%$ of $U(\mathrm{VI})$ and $55 \%$ of Th. This suggests the use of $0.1 \mathrm{M}$ sodium citrate as an internal phase in the LEM investigations to separate U(VI) and Th from other metal ions.

\section{Stability of LEMs}

LEMs are stabilized by surfactant molecules which line up at the interfaces between the membrane and the aqueous phases by appropriate hydrophilic-lipophilic balance value. Stability of an emulsion is greatly influenced by the structure of the surfactant and affects the degree of transport of metal ions through the emulsion membrane. Therefore, the stability of the prepared LEM was studied in terms of the degree of its break-up (leakage), given by the following expression. ${ }^{9}$

$$
\text { Leakage } \%=\left(\left[\mathrm{C}_{\mathrm{ex}}\right] /\left[\mathrm{C}_{\mathrm{in}}\right]_{\max }\right) \times 100
$$

where $\left[\mathrm{C}_{e x}\right]$ denotes the concentration of the tracer in the continous external phase and $\left[\mathrm{C}_{i n}\right]_{\max }$ stands for the maximum possible tracer concentration in the internal phase. Since Cd was not extracted by the investigated system, it was chosen as a tracer in the internal aqueous phase ( $0.1 \mathrm{M}$ sodium citrate) for stability measurements.

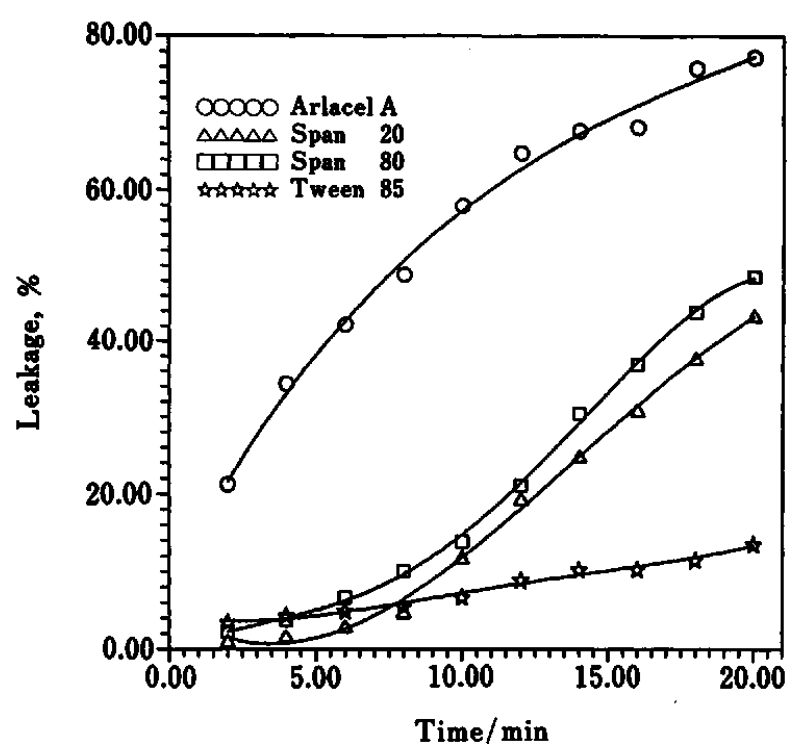

Fig. 3 Effect of the type of surfactant on the leakage $\%$ of LEM.

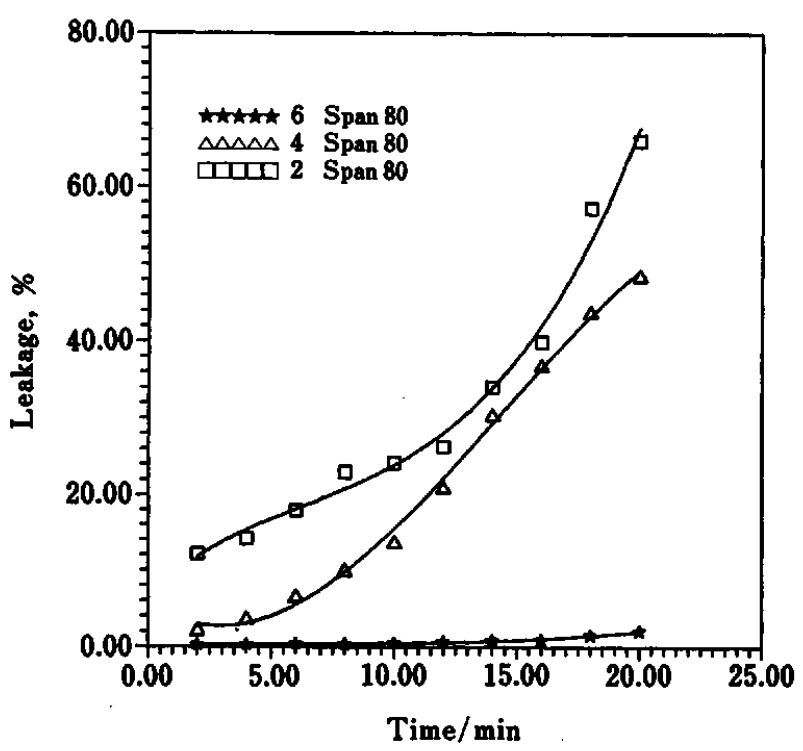

Fig. 4 Effect of Span 80 concentraction on the leakage $\%$ of LEM.

In all stability measurements, the external phase was $100 \mathrm{~cm}^{3}$ of $0.1 \mathrm{M} \mathrm{HNO}_{3}$, the LEM volume was $6 \mathrm{~cm}^{3}$ and the temperature used was $30^{\circ} \mathrm{C}$.

The effect of the type of surfactant on the stability of the emulsion globules was studied. Using a constant surfactant concentration (4\%), the leakage $\%$ as a function of time is given in Fig. 3 for the four different surfactants. Tween 85 showed the highest stability for the emulsion globules, followed by Span 80 and Span 20, whereas Arlacel A* showed the lowest stability. However, it was found that Tween 85 has a disadvantage of forming agglomerates, followed by'coagulation of the emulsion. Therefore, Span 80 was taken as a surfactant 


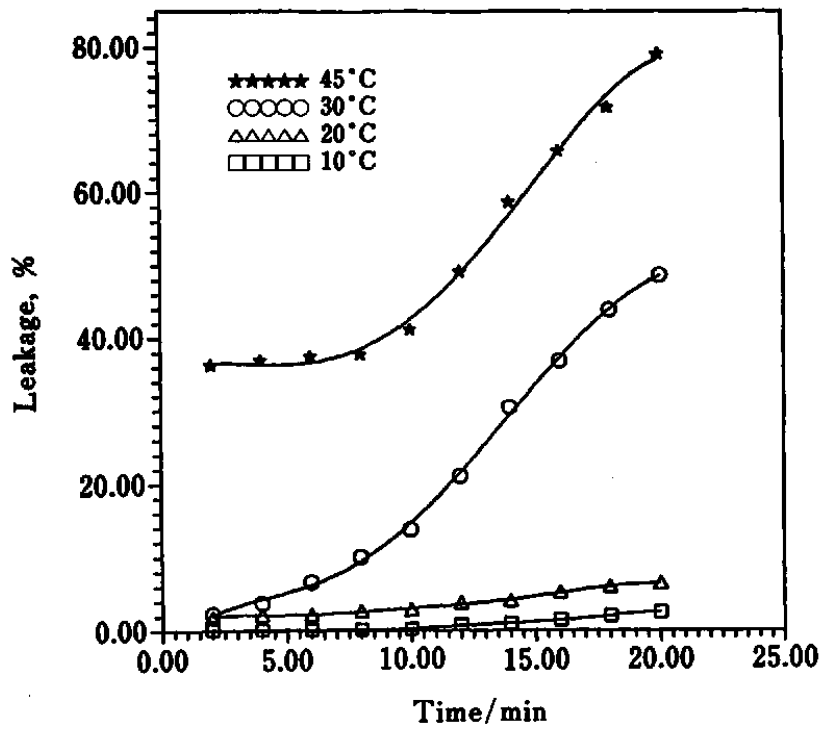

Fig. 5 Effect of temperature on the leakage \% of LEM.

and the effect of its concentration on the emulsion stability was examined. Increasing the concentration of Span 80 from 2 to $6 \%$ in the preparation of the membrane showed an increase in its stability (Fig. 4). Higher surfactant concentration was not tested, since it was reported that high surfactant concentration forms a highly viscous $\mathrm{W} / \mathrm{O}$ emulsion which decreases the rate of metal ions transport through the membrane. ${ }^{9}$

The effect of temperature on the stability of the emulsion globules was studied. The result obtained is given in Fig. 5. It is clear that the stability of the emulsion membrane increases with the decrease in temperature.

The effect of the carrier concentration on the stability of the emulsion was also studied. A carrier concentrations which varied from 0.01 to $0.2 \mathrm{M}$ TOPO in cyclohexane were used. It was found that the emulsion became unstable with increasing the carrier concentration higher than $0.1 \mathrm{M}$ TOPO.

\section{Uranium permeation and kinetics}

Based on the results obtained from the studies on both the liquid-liquid extraction and the stability of the emulsion globules, the general conditions for the permeation of U(VI) by LEM in this study were as follows unless otherwise stated: a $100 \mathrm{~cm}^{3}$ of an aqueous external solution of $0.1 \mathrm{M} \mathrm{HNO}, 6.0 \mathrm{~cm}^{3}$ of an LEM prepared from of $0.1 \mathrm{M}$ TOPO and $4 \%$ Span 80 in cyclohexane together with $0.1 \mathrm{M}$ sodium citrate aqueous solution $(\mathrm{pH}=8.5)$. All experiments were carried out at $30^{\circ} \mathrm{C}$.

The permeation percent of U(VI) at equilibrium is given in Tables $2 a$ and $2 b$ together with the time at which equilibrium was reached. Each parameter was studied separately by keeping the others constant. From this table it is clear that the permeation percent of U(VI)
Table 2a Effect of $\left[\mathrm{HNO}_{3}\right]$ and [U(VI)] in the external phase solution on the permeation \% of U(VI) at constant [TOPO] $=0.1 \mathrm{M}$ and $[\mathrm{Na}$ citrate] $=0.1 \mathrm{M}$

\begin{tabular}{ccccc}
\hline $\begin{array}{c}{\left[\mathrm{HNO}_{3}\right] /} \\
\mathrm{M}\end{array}$ & $\begin{array}{c}{[\mathrm{U}(\mathrm{VI})] /} \\
\mathrm{M}\end{array}$ & $\begin{array}{c}\text { Time }_{\text {equ}} / \\
\min \end{array}$ & $\begin{array}{c}\text { Permeation, } \\
\%\end{array}$ & $k / \mathrm{s}^{-1}$ \\
\hline 0.001 & $5.00 \times 10^{-4}$ & 15 & 58.0 & 0.059 \\
0.001 & $5.00 \times 10^{-4}$ & 11 & 79.0 & 0.090 \\
0.100 & $5.00 \times 10^{-4}$ & 11 & 80.0 & 0.142 \\
1.00 & $5.00 \times 10^{-4}$ & 11 & 96.0 & 0.190 \\
3.00 & $5.00 \times 10^{-4}$ & 11 & 87.0 & 0.154 \\
5.00 & $5.00 \times 10^{-4}$ & 11 & 85.0 & 0.139 \\
0.10 & $2.50 \times 10^{-4}$ & 11 & 90.0 & 0.214 \\
0.10 & $5.00 \times 10^{-4}$ & 11 & 80.0 & 0.143 \\
0.10 & $7.50 \times 10^{-4}$ & 11 & 76.0 & 0.126 \\
0.10 & $1.25 \times 10^{-3}$ & 13 & 74.0 & 0.090 \\
0.10 & $1.75 \times 10^{-3}$ & 13 & 44.0 & 0.070 \\
\hline
\end{tabular}

Table 2b Effect of [TOPO] and [Na citrate] in the internal phase on the permeation \% of U(VI) at constant $\left[\mathrm{HNO}_{3}\right]=$ $0.1 \mathrm{M}$ and $[\mathrm{U}(\mathrm{VI})]=5 \times 10^{-4} \mathrm{M}$

\begin{tabular}{ccccc}
\hline [TOPO]/ & {$[$ Na citrate]/ } & Time $_{\text {equ }} /$ & $\begin{array}{c}\text { Permea- } \\
\text { tion, }\end{array}$ & $k / \mathrm{s}^{-1}$ \\
$\mathbf{M}$ & $\mathrm{M}$ & $\min$ & $\%$ & \\
\hline $1 \times 10^{-3}$ & $1 \times 10^{-1}$ & 9 & 5.8 & 0.002 \\
$1 \times 10^{-2}$ & $1 \times 10^{-1}$ & 11 & 15.0 & 0.015 \\
$5 \times 10^{-2}$ & $1 \times 10^{-1}$ & 11 & 37.0 & 0.075 \\
$1 \times 10^{-1}$ & $1 \times 10^{-1}$ & 11 & 80.0 & 0.140 \\
$2 \times 10^{-1}$ & $1 \times 10^{-1}$ & 13 & 96.0 & 0.280 \\
$1 \times 10^{-1}$ & $1 \times 10^{-2}$ & 7 & 75.0 & 0.123 \\
$1 \times 10^{-1}$ & $1 \times 10^{-1}$ & 11 & 70.0 & 0.142 \\
$1 \times 10^{-1}$ & 1.0 & 13 & 93.0 & 0.141 \\
\hline
\end{tabular}

increased with the increase of $\mathrm{HNO}_{3}$ concentration from 0.001 to $1 \mathrm{M}$ in the external solution and that it decreases with the increase of $\mathrm{HNO}_{3}$ concentration from 1 to $5 \mathrm{M}$. On the other hand, the permeation percent decreases with the increase of $U(V I)$ concentration in the external solution. Increasing the carrier or strippant concentration shows a regular increase in the permeation percent.

In order to get a quantitative measure of the kinetics of uranyl ion complexation and permeation, the following simple first order rate equation was applied: ${ }^{10}$

$$
[\mathrm{M}] /\left[\mathbf{M}_{\mathrm{o}}\right]=\mathrm{e}^{-k t}
$$

and

$$
\ln \left([\mathrm{M}] /\left[\mathrm{M}_{0}\right]\right)=-k t
$$

where $[M]$ is the time dependent concentration of $U$ in the external phase solution, $\left[\mathrm{M}_{\mathrm{o}}\right]$ is the initial concentration, $t$ is the resident time and $k$ is the rate constant which characterizes the complexation kinetics.

Plotting $\ln \left([\mathrm{M}] /\left[\mathrm{M}_{0}\right]\right)$ against $t$ for the different parameters produced straight lines. The values of the rate constant $k$ were determined from the slopes in each 


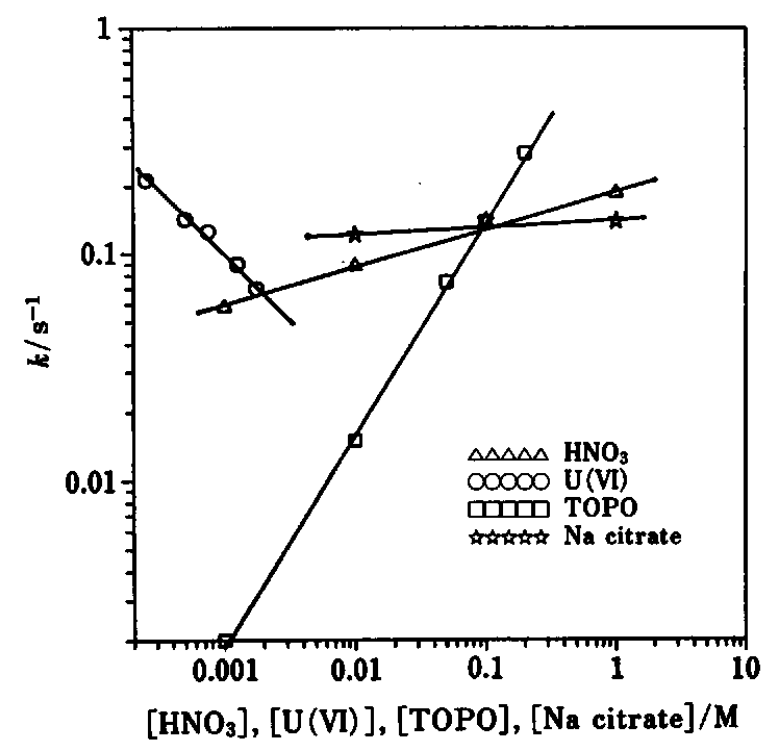

Fig. 6 The $\log -\log$ relation between $k$ and [HNO ${ }_{3}$, [U(VI)], [TOPO], and [Na citrate].

case, and are given in Tables $2 a$ and $2 b$.

Plotting $\log k$ versus the logarithm of the variable under investigation gives its power dependency (Fig. 6). From this figure, it is clear that the rate constant slightly depends on $\mathrm{U}(\mathrm{VI})$ and $\mathrm{HNO}_{3}$ concentrations in the external phase where slopes of -0.6 and 0.3 were obtained, respectively. Concerning the LEM composition, the rate constant was found to be independent of the strippant concentration while a slope of unity is obtained for the carrier concentration. From these data, the rate of $\mathrm{U}(\mathrm{VI})$ permeation, at $30^{\circ} \mathrm{C}$ and at the ratio of membrane to external phase volume of $6: 100$, can be represented by the following relation:

$$
\mathrm{d}[\mathrm{M}] / \mathrm{d} t=\mathrm{K}\left[\mathrm{HNO}_{3}\right]^{0.3}[\mathrm{U}(\mathrm{VI})]^{-0.6}[\mathrm{TOPO}]^{1}
$$

\section{Separation of $U$ and Th from other metal ions}

In a trial to increase the permeation of U(VI) more than $80 \%$ which was obtained using the above-mentioned conditions, the ratio of membrane to external phase volume was increased to $10: 100$. Thus, to $100 \mathrm{~cm}^{3}$ solution of $0.1 \mathrm{M} \mathrm{HNO}_{3}$, containing $120 \mu \mathrm{g} / \mathrm{cm}^{3}$ of $\mathrm{U}(\mathrm{VI})$, and $1000 \mu \mathrm{g} / \mathrm{cm}^{3}$ of Th together with $120 \mu \mathrm{g} / \mathrm{cm}^{3}$ of each of the metal ions $\mathrm{Zr}, \mathrm{Ce}, \mathrm{Fe}(\mathrm{III}), \mathrm{Cu}$, and $\mathrm{Cd}$, a $10 \mathrm{~cm}^{3}$ portion of the membrane prepared (as given in the experimental section) was added. Under such conditions, the permeation of the investigated metal ions was studied. The data obtained are illustrated in Fig. 7 . It was found that approx. 98\% U(VI) is permeated together with $82 \%$ of Th after $9 \mathrm{~min}$, while less than $2 \%$ of $\mathrm{Fe}$ (III) is permeated. Concerning the other metal ions, no detectable permeation was observed.

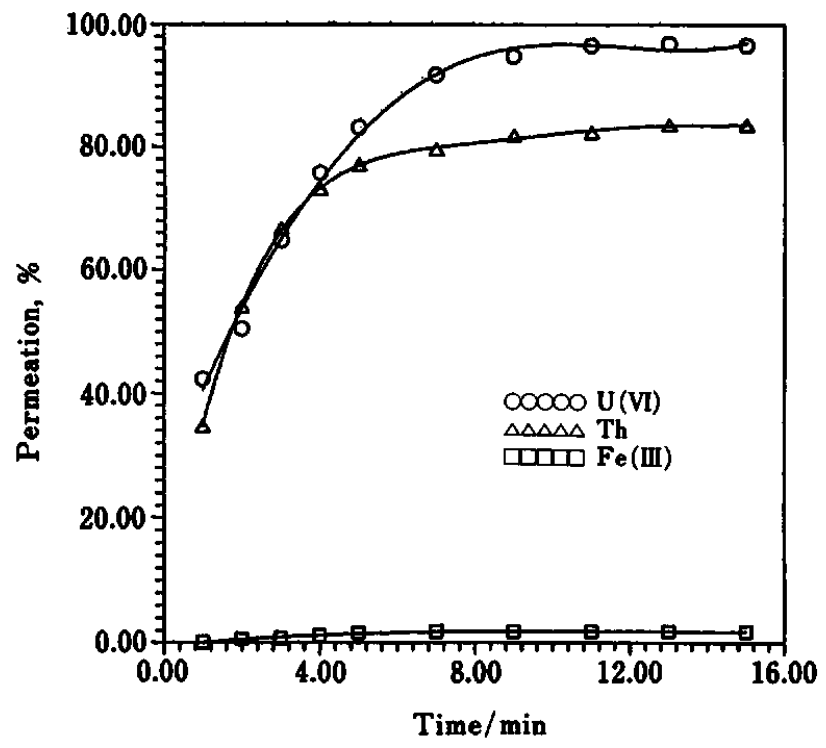

Fig. 7 Plot of permeation \% of U(VI), Th and Fe(III) against time using $10: 100(v / v)$ of LEM : external phase ratio.

\section{References}

1. N. N. Li, US Patent, 3,410,794 (1968).

2. F. Macasek, P. Pajec, V. Rehacek, Vu Nogocanh and T. Popovkakova, J. Radioanal. Nucl. Chem., 96, 529 (1985).

3. J.-H. Yoo, K.-W. Kim and H. S. Park, Proceeding of International Solvent Extraction Conference, ISEC 88, Moscow Vol. III, p. 101 (1988).

4. H. C. Hayworth, W. S. Ho, W. A. Burns and N. N. Li, Sep. Sci. Technol, 18, 493 (1983).

5. R. P. Cahn, J. W. Frankenfeld and N. N. Li, "Recent Developments in Separation Science", Vol. 6, p. 51, CRC Press, Bóca Raton, 1981.

6. H. F. Aly, S. A. El-Reefy and E. A. El-Sherif, Proceeding of International Solvent Extraction Conference, ISEC 93, York, UK, Vol. II, p. 788 (1993).

7. S. A. El-Reefy, A. E. El-Sherif and H. F. Aly, J. Radioanal. Nucl. Chem., Articles, 207, 129 (1996).

8. Z. Marczenko, "Spectrophotometric Determination of Elements", John Wiley and Sons, Inc., New York, 1986.

9. M. Teramoto, T. Sakai, K. Yanagawa, M. Ohsuga and Y. Miyake, Sep. Sci. Technol, 18, 735 (1983).

10 M. Teramoto, T. Sakaramoto, T. Koyama, H. Matsuyama and Y. Miyake, Sep. Sci. Technol, 21, 229 (1986).

(Received November 20, 1996) (Accepted March 4, 1997) 